\title{
ORGANIZATION ORDER OF INVESTIGATION AND EVALUATION OF THE INNER SYSTEM CONTROL
}

\author{
Shavkat ILKHAMOV \\ Tashkent state University of Economics, Uzbekistan
}

\begin{abstract}
The existence of weaknesses in the internal control system should concern auditors because it provides an indication of risk that a material misstatement in the annual or interim financial statements will not be prevented or detected by the system of internal controls. Therefore, the knowledge of a problem in the internal controls should cause auditors to adjust their risk assessment and/or level of testing. If so, risk-adjusted audit pricing should yield higher audit fees for companies with problems ineffective disclosure controls.
\end{abstract}

\section{JEL CLASSIFICATION \& KEYWORDS}

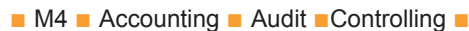

\section{INTRODUCTION}

One of the main and key stages at organizing and carrying out auditing is the evaluation of the system of inner control of the organization being audited.

The main requirements, submitted to investigation and evaluation of the inner system control by an auditor are formulated in the National Standards of Auditing (further NSA 12). ${ }^{1}$

It is necessary to note that for working out the NSA 12 the International Standards of Auditing (ISA) as well as the expertise of the Russian Federation were as a basis. The main principles and requirements introduced in it correspond to the generally accepted international practice and are the element of the system of normative regulation of the auditing activity in the Republic.

As control is one of the functions of management, it is clear that organization and keeping the inner system control is such a process which assists the administration in managing the given organization.

Therefore the existing normative acts (Article 7 of the Law of the Republic of Uzbekistan "About Accounting", item of 20 of the NSA 12) commit the administration of the organization to work out the and apply the inner system control. At the same time the inner system control being applied should correspond and meet the scales and specify of the activity of the organization and function regularly and effectively.

This system can be effective or non-effective due to its ability to solve the given tasks and to protect the organization from the possible risks. The service of inner control system cannot be absolutely sure but with some degree of probability confirm that the goals put forward were achieved.

This limitation inherent to the service of the inner control has various manifestations beginning from completely corresponding ones to the legislation and completely contradicting ones to it.

${ }^{1}$ National Standard of the Auditing Activity of the Republic of Uzbekistan. "The evaluation system of accounting and inner control during auditing "(registered by the Ministry of Justice, 1673 dated from 12.04.2007.).

\section{MAIN TEXT}

Thus, the demand of the administration that the expenses spent on carrying out control measures and procedures should be less than the economic benefits received from the application of such measures corresponds to the requirements of conducting accounting and at the same time the designed violation of the inner control service as a result of some employees of the organization with others for carrying out roguish (fraud) actions contradict the legislation of the Republic of Uzbekistan.

So the effective system of the inner control of the organization presupposes the division of responsibilities and authorities of the employees and must exclude the violations of the requirements by separate persons and secure the division of incompatible functions.

The functions of an employee are incompatible if their concentration in the hands of one person may promote committing casual and designed shortcomings and violations and hamper finding out such shortcomings and violations. It is necessary to note that the presents of effectively functioning of the inner control system is the most important factor of the grows of the enterprise competitiveness. For securing the efficiency of the inner control system some functions in practice are distributed among various persons (Figure 1).

Figure 1: The functions of the inner control system to be distributed

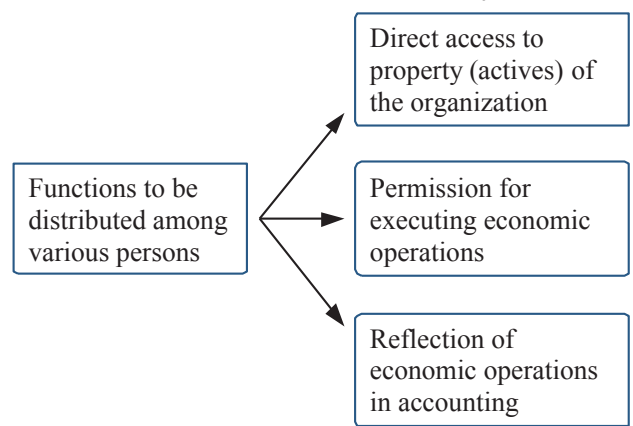

source: Author

Proper functioning of the inner control system depends also from the employees who are responsible for the corresponding activity. The system of selection, hiring, carrier promotion, instruction and training of the personnel must secure high qualification of the corresponding personnel.

In the end the manager of the organization is responsible for creating effective system of the inner control, forming the means of control in the organization and for timely informing all the official persons about all considerable risks standing before the organization.

The process of organization and maintaining the inner control system can be executed by the manager himself of 
the organization as well as in accordance with the legislation on the charter of the organization the inner auditing department or another department can be formed which will execute the inner control or part of its functions.

For the successful functioning of the organization it is necessary a well-aligned management mechanism, the important element of which is a regularly working inner control system.

The main task of the system of the inner control is to secure observation and auditing the functioning of any part of an enterprise, its branches and subsidiaries if their activity is in accordance with the laws, normative documents, regulations and orders taken by the management.

Establishing deviations from the requirements of these documents and finding out the causes of their emergence the inner control system assists timely the owners and/or executive management to work out and to realize some measures aimed at its optimal functioning.

Speaking about the inner control it is important to realize that it is useful only in a case if it is directed at the achievement of some definite aims and above all before evaluating the results of the inner control it is necessary to define these goals (Figure 2)

Figure 2. The main goals of the inner control system

\begin{tabular}{|l|l|}
\hline \multicolumn{2}{|c|}{ The main goals of the inner control system } \\
\hline & Reliability and completeness of the information \\
\hline & Correspondence to policy plans, procedures, legislation \\
& Securing the safe keeping of assets \\
\hline & Economical and efficient use of resources \\
\hline & Achievement of the goals and tasks put forward by the \\
subdivisions of the enterprise
\end{tabular}

In accordance with the National Standard of the Auditing Activity (NSA 12) the inner control system is the whole complex of organizational measures, methodic and procedures (the inner control means), accepted by the management of an enterprise with the aim of affective running and control of financial - economic activity, securing the intactness of assets and accounting documents, preventing and finding out the cases of fraud and faults, the accuracy and completeness of accounting figures and timely preparation of trustworthy financial information.

For all that at the stage of investigating and evaluating the tasks of the inner control system are of great significance and an auditor should pay attention to them (Figure 3).

Figure 3. The main tasks of the inner control system

\begin{tabular}{|l|l|}
\hline & The main tasks of the inner control system \\
\hline & $\begin{array}{l}\text { Documenting existing key and new business processes, } \\
\text { evaluating risks and introduction of inner control procedures }\end{array}$ \\
& $\begin{array}{l}\text { Working out proposals on optimization of business process } \\
\text { and document turnover, recommendation on decreasing risks } \\
\text { and negative effects of their influence }\end{array}$ \\
& $\begin{array}{l}\text { Monitoring of the efficiency of the introduced inner control } \\
\text { procedures periodically }\end{array}$ \\
$\longrightarrow$ & $\begin{array}{l}\text { Interaction with the enterprise subdivisions on the questions } \\
\text { of forming of the inner control system }\end{array}$ \\
\hline
\end{tabular}

Source: Author forming of the inner control system

While evaluating the inner control system an auditor ought to take into account the fact that the inner control system cannot with absolute accuracy but with some definite degree of probability confirm that the goals for the sake of which it was created were achieved because of the following limitations of the inner control system (item 23 of NSA 12) (Figure 4).

In the course of planning an auditor must be sure that the control means of an enterprise being checked gain the following goals:

a) the economic operations are being fulfilled by the approval of the management as a whole as well as in concrete cases;

b) all the operations are registered in the accounting calculation in the correct sums on the proper accounts of the accounting calculation with the correct period of time, in accordance with the calculation policy accepted at the enterprise and secure the possibility of preparing a trustworthy financial report;

c) access to the assets is possible only with the permission of the corresponding management;

d) the correspondence of the assets registered in accounting and available ones is defined by the responsible officials periodically and in a case of discrepancy the management takes the necessary actions.

Figure 4. Limitations of the inner control system

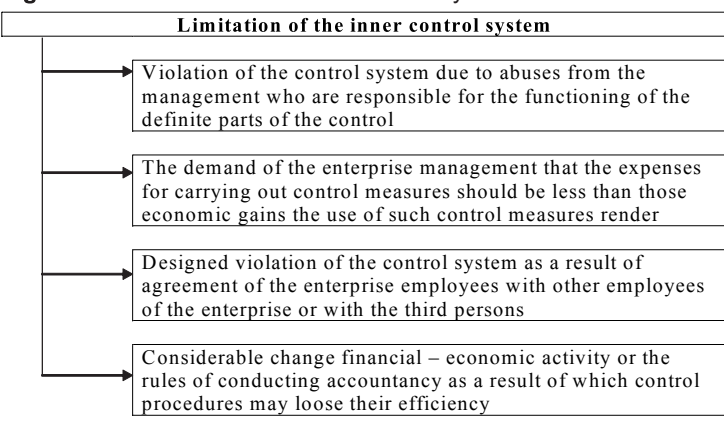

Source: Author procedures may loose their efficiency

It is also necessary for an auditor to be sure of the application of the following inner control procedures at the enterprise being audited:

a) the use of the information from the outer sources for the goals of control;

b) checking the correctness of carrying out the document turnover and availability of permittance writings of the management;

c) carrying out the measures directed to the physical limitation of the access of the non-authorized persons to the enterprise assets, to keeping documentation and accounting records;

d) arithmetic checking of the accounting records;

i) investigation of the dynamics of the indices, comparison of planned and the estimate indices with the factual ones and clearing out the causes of discrepancies;

j) carrying out in accordance with the established order the periodical, planed and unexpected inventories of the assets with the aim of correspondence of the accounting data with the actual ones;

e) carrying out collation of calculations.

It is necessary to take in to account that the procedures of conforming the trustworthiness of the inner control system and (or) separate means of control are executed on the basis of methodics and modes which are worked out the auditing organization independently taking in to account the 
Printed from: Serif PagePlus 14,0,5,27 Copyright ( $1994-2009$ Serif (Europe) Ltd. All Rights Reserved

Printed on: 28.3.2011 18:39:46

Publication name: Journals.cz_EJBE_Vol2.ppp, Page: 35

VOLUME 2, 2011

requirements of the National Standard of the Auditing Activity (item 35 of NSA 12)

\section{CONCLUSION}

According to our opinion for the effective functioning of the enterprise's inner control system it is necessary to delimit the authority of the subdivisions entering in to the inner control system which directly work out approve and apply the control procedures and the evaluate the inner control system. In the approved reglamentations and principles for each control subdivision of an enterprise the field of authority responsibilities and interactions with other control subdivisions, the list, periodicity, and the order of the carrying out the control procedures should be defined.

\section{REFERENCES}

1. Law of the Republic of Uzbekistan "About Accounting". Tashkent, 1996.

2. Law of the Republic of Uzbekistan «Of public accountant activity». Tashkent, 2000.

3. National Standard of the Auditing Activity of the Republic of Uzbekistan 12-"The evaluation system of accounting and inner control during auditing "(registered by the Ministry of Justice, 1673 dated from 12.04.2007.).

4. Collection of international standards of audit. Expression to the confidence and ethics - Almaty, 2007

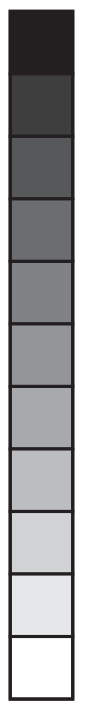

